\title{
Evaluation of the Quality of Life of Gynecological Cancer Patients Submitted to Antineoplastic Chemotherapy
}

\author{
Lívia Loamí Ruyz Jorge ${ }^{1}$
}

Sueli Riul da Silva²

This study aimed to evaluate the quality of life of female gynecological cancer patients submitted to antineoplastic chemotherapy Between August 2007 and April 2009, 50 patients who were undergoing chemotherapy at an outpatient chemotherapy unit in Uberaba - MG were interviewed, by applying the instrument of evaluation of Quality of Life of the World Health Organization, WHOQOL-BREF. The results showed that the domain most affected was the Physical and the more preserved, the Social, with the mean of the general quality of life above the means obtained in other studies. All domains correlated significantly with the general quality of life. It was evident then that the quality of life of these women is satisfactory, however it is suggested that the domains with lower scores be the targets of more accurate observations during multi-professional interventions in order to provide a better quality of life during the chemotherapy treatment.

Descriptors: Oncologic Nursing; Quality of Life; Drug Therapy; Neoplasms.

\footnotetext{
Universidade Federal do Triângulo Mineiro, Brazil:

${ }^{1}$ Nursing undergraduate student. Basic Cientific Scholarship holder, CNPq. E-mail: enf_livia@yahoo.com.br.

${ }^{2}$ RN, Ph.D. in Nursing, Associate Professor. E-mail: sueliriul@terra.com.br.
} 


\section{Avaliação da qualidade de vida de portadoras de câncer ginecológico, submetidas à quimioterapia antineoplásica}

Este estudo teve como objetivo avaliar a qualidade de vida de mulheres portadoras de câncer ginecológico, submetidas à quimioterapia antineoplásica. Foram entrevistadas 50 pacientes, no período de agosto de 2007 a abril de 2009, que estavam em tratamento quimioterápico em um ambulatório de quimioterapia de Uberaba, MG, mediante aplicação do instrumento de avaliação de Qualidade de Vida da Organização Mundial da SaúdeWHOQOL-bref. Os resultados apontaram que o domínio mais comprometido foi o físico e o mais preservado, o social, sendo que a qualidade de vida geral obteve média acima da obtida em outros estudos. Todos os domínios correlacionaram-se significativamente com a qualidade de vida geral. Pode-se evidenciar, então, que a qualidade de vida dessas mulheres é satisfatória; entretanto, sugere-se que os domínios com escores mais baixos sejam alvo de observações mais acuradas, durante as intervenções multiprofissionais, a fim de se proporcionar melhor qualidade de vida durante o tratamento quimioterápico.

Descritores: Enfermagem Oncológica; Qualidade de Vida; Quimioterapia; Neoplasias.

\section{Evaluación de la calidad de vida de portadoras de cáncer ginecológico, sometidas a quimioterapia antineoplásica}

Este estudio tuvo como objetivo evaluar la calidad de vida de mujeres portadoras de cáncer ginecológico sometidas a quimioterapia antineoplásica. Fueron entrevistadas 50 pacientes en el período de agosto de 2007 a abril de 2009 que estaban en tratamiento quimioterapéutico en un ambulatorio de quimioterapia de Uberaba-MG, mediante la aplicación del instrumento de evaluación de Calidad de Vida de la Organización Mundial de la Salud-WHOQOL-bref. Los resultados apuntaron que el dominio más comprometido fue el físico y el más preservado, el social, siendo que la calidad de vida general obtuvo un promedio superior al obtenido en otros estudios. Todos los dominios se correlacionaron significativamente con la calidad de vida general. Se puede evidenciar, entonces, que la calidad de vida de esas mujeres fue satisfactoria; sin embargo se sugiere que los dominios con puntajes más bajos sean examinados con observaciones más exactas durante las intervenciones multiprofesionales, a fin de proporcionar una mejor calidad de vida durante el tratamiento quimioterapéutico.

Descriptores: Enfermería Oncológica; Calidad de Vida; Quimioterapia; Neoplasias.

\section{Introduction}

Cancer is incident in the population in an overwhelming way, due to the demographic transition we are experiencing today, as well as the growing exposure of the population to carcinogens in the environment. Gynecologic cancer, especially breast and cervical cancer remain the most common among women, with estimates, for Brazil, of more than 70,000 new cases for the year 2010(1).

The use of antineoplastic chemotherapy as a systemic therapeutic resource against cancer, is proving to be ever more promising, given the purification of drugs, and the development of administration protocols that allow the concurrent use of more than one compound, as well as the reversing of side effects by applying rescue, symptomatic and protective therapy ${ }^{(1-3)}$.

In this context, nursing has been participating in cancer control initiatives and has been consistently assuming care actions in the administration of various treatments for disease, particularly antineoplastic chemotherapy ${ }^{(3)}$. There is an increasing emphasis on evaluating the quality of life of people treated for cancer, due to factors such as advances in the detection 
and treatment of the disease, more optimistic social attitudes, the increase in the number of survivors, the concern with the autonomy and rights of patients, the role of psychosocial factors, the extent of survival, among others ${ }^{(4-5)}$.

The World Health Organization (WHO) defines quality of life as "an individual's perception of his/her position in life in the context of the culture and value systems in which he/she lives, and in relation to his/her goals, expectations, standards and concerns"(4). However, to assess or measure quality of life is a complex task, given the subjective nature of the subject. Therefore, the proposed use of an instrument for assessing quality of life, valid for all human groups, by the WHO, aims to homogenize the concept and to provide professionals with a technical-scientific, standardized and consistent tool(6). The instrument proposed by the WHO evaluates quality of life in domains denominated as Physical, Psychological, Social relationships and Environment that interpret the perception that the individuals have of themselves and their surroundings, as favorable or $\operatorname{not}^{(6)}$.

In our professional pathway we have been keen to develop studies and practices related to immediate and delayed side effects of antineoplastic chemotherapy, and to assess the impact of this treatment in the lives of patients with gynecologic cancer. There is a need, however, for a thorough and systematic study, based on a consistent and consolidated instrument for evaluating the quality of life of patients during treatment, in order to respond ever more effectively and efficiently to their needs, considering, the integral aspect of the individual, aiming for a holistic therapeutic proposal.

Our proposal is justified because it contributes to the construction of knowledge of oncology nursing related to the quality of life of those who undergo aggressive treatment for cancer, and has sought to understand the life situations of people with cancer(7).

This study therefore aims to evaluate the quality of life of patients with gynecologic cancer undergoing antineoplastic chemotherapy, by applying the instrument proposed by the WHO, the WHOQOL-BREF.

\section{Methods}

This descriptive and cross-sectional study was developed in the Chemotherapy Centre of the Clinical Hospital of the Federal University of Triangulo Mineiro (UFTM), which aims for care, teaching and research.

The study population consisted of all patients with gynecological cancer over 18 years of age, undergoing antineoplastic chemotherapy, who agreed to participate in the study by understanding and signing the Terms of Clarification and Consent respectively, from August 2007 to April 2009. An opportune moment for the interview was understood to be 10-14 days after administration of the third cycle of chemotherapy. This moment was chosen for the application of the data collection instrument because this is a moment for which all patients would pass, as some treatments are composed of three, four, six or more cycles, being a minimum of three.

Data collection was performed in two stages: firstly, all patients undergoing chemotherapy and residents of Uberaba were interviewed, with the interviews conducted during pre-scheduled home visit (August 2007 to July 2008); secondly, patients that were non-residents of Uberaba were included in the study, and data collection began to be performed at Chemotherapy Central during their treatment (from July 2008 to April 2009). This extension to the study was justified by the observation that data collection could be performed during treatment and that with this a larger number of patients could be addressed.

In the period described, there were 71 patients undergoing chemotherapy at the research site, two refused to participate in the study, one had no cognitive conditions to answer the questionnaire and 18 were excluded, in the first stage of data collection, due to not residing in Uberaba, totaling, therefore, a population of 50 individuals.

Data were collected in private, the interviews being carried out in the room where the patients received chemotherapy. Due to the infusion often lasting several hours and, according to the experience of the researchers in the service and the staff of the site, this being the best place for the interview. Although most of the time, a family member was present at the venue, they were asked not to intervene. Before starting the interviews, all were once again informed of the research objectives, the confidentiality of information obtained, as well as the mode of application and the destination of the data, being asked to sign a terms of consent form.

To collect the data, the WHOQOL-BREF was used, a shortened version in Portuguese of the Quality of Life Assessment Instrument of the WHO, validated for the Brazilian culture(6). This instrument consists of two parts, the first being an information form about the Respondent, which is designed to collect socio-demographic and health data of the subjects. The second part, about quality of life itself, is composed of 26 questions, two on general quality of life and the remaining 24 representing four domains 
and their facets that make up the original instrument, of Physical, Psychological, Social relationships and Environment domains.

The answers to all questions of the WHOQOLBREF are obtained through a Likert type scale of five points, in which scores can range from 1 to 5 . Both the domains and the general quality of life are measured in the positive direction, i.e. higher scores denote higher quality of life. To calculate the domain scores, we used the syntax provided by the WHOQOL Group for use in the software program SPSS (Statistical Package for Social Science). With it, the program can check, recode and establish domain and questions of general quality of life scores.

For data analysis, descriptive statistics (frequency, proportion, means of position and dispersion) and the Pearson's coefficient were used to evaluate the correlation of each domain with the general quality of life. The value of $p<0.05(\alpha=5.0 \%)$ was adopted as the critical level.

To develop the study, advice and consent was sought and obtained from the Human Research Ethics Committee of the Institution (protocol No. 709/2006).

\section{Results}

Fifty patients were interviewed, 12 of whom $(24.0 \%)$ were between 20 and 39 years of age, 24 (48.0\%) between 40 and 59 years, and 14 (28.0\%) aged 60 years or over, with a mean age of 48.4 ( \pm $12.0)$ years. Regarding educational level, three $(6.0 \%)$ were illiterate, $31(62.0 \%)$ had incomplete primary education, four $(8.0 \%)$ complete primary education, one $(2.0 \%)$ incomplete high school, nine (18.0\%) completed high school, one $(2.0 \%)$ incomplete higher education and one (2.0\%) complete higher education. In relation to marital status, $11(22.0 \%)$ were single, $26(52.0 \%)$ married, four $(8.0 \%)$ were cohabiting, two $(4.0 \%)$ separated, two $(4,0 \%)$ divorced and five (10.0\%) widowed.
Regarding the type of cancer, 29 (58.0\%) were suffering from breast cancer, 11 (22.0\%) from cervical cancer, eight (16.0\%) from ovarian cancer, one $(2,0 \%)$ from endometrial cancer and one $(2.0 \%)$ from vaginal cancer. Questioned regarding self-rated health, 20 patients $(40.0 \%)$ classified it as "very good" or "good", $16(32.0 \%)$ as "neither good nor bad" and 14 (28.0\%) as "very bad" or "weak". In relation to satisfaction with health, 27 (54.0\%) were "satisfied", 14 (28.0\%) "neither satisfied nor dissatisfied" and nine (18\%) "dissatisfied" or "very dissatisfied".

Regarding treatment protocols, 20 patients (40.0\%) were using epirubicin and cyclophosphamide (EC), 11 (22.0\%) used cisplatin, etoposide and bleomycin (PEB), nine (18\%) paclitaxel and ten (20\%) were using other protocols. Frequency distributions of the protocols used with the scores obtained for each of these are described in Table 1.

Table 1 - Frequency of treatment protocols and scores obtained using the WHOQOL-BREF for patients in outpatient chemotherapy $(n=50)$. Uberaba, 2009

\begin{tabular}{|c|c|c|c|}
\hline Treatment Protocol & $\mathrm{N}^{\circ}$ of Patients & $\%$ & Score \\
\hline Epirubicin and cyclophosphamide & 20 & 40.0 & 63.7 \\
\hline Cisplatin, etoposide and bleomycin & 11 & 22.0 & 75.0 \\
\hline Paclitaxel & 09 & 18.0 & 61.1 \\
\hline $\begin{array}{l}\text { Cisplatin, epirubicin and } \\
\text { cyclophosphamide }\end{array}$ & 02 & 6.0 & 43.8 \\
\hline Cisplatin and cyclophosphamide & 03 & 6.0 & 33.3 \\
\hline Paclitaxel and cyclophosphamide & 02 & 4.0 & 75.0 \\
\hline Cisplatin and 5-fluorouracil & 01 & 2.0 & 75.0 \\
\hline $\begin{array}{l}\text { Cyclophosphamide, methotrexate } \\
\text { and 5-fluorouracil }\end{array}$ & 01 & 2.0 & 62.5 \\
\hline $\begin{array}{l}\text { 5-fluorouracil, epirubicin and } \\
\text { cyclophosphamide }\end{array}$ & 01 & 2.0 & 62.5 \\
\hline
\end{tabular}

The results obtained in the evaluation of quality of life with the WHOQOL-BREF are shown in Table 2. It was observed that the most compromised domains were the Physical and Environment domains, and the most preserved, the Social domain.

Table 2 - Scores obtained using the WHOQOL-BREF of patients in outpatient chemotherapy $(n=50)$. Uberaba, 2009

\begin{tabular}{|c|c|c|c|c|c|}
\hline Domains & Mean & Standard deviation & Median & Minimum & Maximum \\
\hline Physical & 56.0 & 13.5 & 57.1 & 21.4 & 85.7 \\
\hline Psychological & 62.6 & 12.3 & 62.5 & 16.7 & 83.3 \\
\hline Social & 71.0 & 15.6 & 75.0 & 16.7 & 100.0 \\
\hline Environment & 58.1 & 12.6 & 56.2 & 31.2 & 93.7 \\
\hline General quality of life & 68.6 & 16.8 & 75.0 & 12.5 & 100.0 \\
\hline
\end{tabular}


All domains correlated positively and significantly with the general quality of life, the Psychological domain with a strong magnitude, and the other with moderate magnitude, as can be observed in Table 3 .

Table 3 - Correlation between the domains of WHOQOL-BREF and of these with the Quality of Life of patients in outpatient chemotherapy $(n=50)$. Uberaba, 2009

\begin{tabular}{cccc}
\hline \multirow{2}{*}{ Domains and General quality of life } & \multicolumn{2}{c}{ Domains } \\
\cline { 2 - 4 } & Physical & Psychological & Social \\
\hline General quality of life & $0.55^{*}$ & $0.67^{*}$ & $0.40^{*}$ \\
\hline
\end{tabular}

$* p<0.05$

\section{Discussion}

The data analysis allows the comprehension that the age group of highest incidence of gynecological cancers is over 40 years of age, which is consistent with information provided by the INCA - National Cancer Institute. This highlights the importance of screening this population with preventive examinations and guidance regarding lifestyle, prevention and early detection of cancer in the age group 20-49 years $^{(8)}$.

Breast cancer stood out as the most common neoplasia among women, followed by cervical cancer, supporting the literature. According to the INCA, breast cancer stands out as the most frequent in the female population of the Southeast of Brazil, with an estimate for 2010 of 65 new cases for every 100,000 women. Without considering non-melanoma skin tumors, this type of cancer is also the most frequent among women from the South $(64 / 100,000)$, Midwest $(38 / 100,000)$ and Northeast $(30 / 100,000)$, whereas in the North it is the second most prevalent (17 per 100,000$)^{(1-2,4)}$. However, cervical cancer is the second most frequent among the Brazilian female population and represents one of the most frequent causes of death in the female population in Latin America, where incidence rates are among the highest in the world(9).

Regarding self-rated health, most of the interviewees rated it as very good or good and considered that they are satisfied with it. This result indicates that, in view of the prospect of progress of a chronic disease, they are satisfied with the moment they are experiencing.

With regard to quality of life, it was observed that the Physical domain was the most compromised (score 56.0). This fact can be explained by the toxicity of chemotherapy drugs administered, in relation to cellular non-specificity, which can generate effects such as pain, fatigue, nausea and vomiting, and additionally anorexia, hampering clients in their daily activities and thus reducing their quality of life $\mathrm{e}^{(3,10)}$. Thus, this should be investigated and actions proposed to more effectively control these effects.

The second most compromised domain was the Environment (score 58.1), indicating that these clients consider themselves to have some difficulties related to the conditions of where they live, security, transportation, economic conditions and opportunities for recreation and leisure. Studies show that leisure is altered after breast cancer, especially in patients with Iymphedema, because they feel social discomfort due to the increase in size of the limb and there is also decrease in the intensity, quantity and time devoted to activities previously practiced such as sunbathing, gardening and physical activities. Moreover, many women leave or diminish their professional work, which ultimately affects their family financial condition ${ }^{(11-12)}$. To help women find alternative leisure opportunities, and inform them as to their rights as women with cancer are ways to minimize the environmental impact in their quality of life.

Due to the diverse changes occurring in the family routine, and the impact caused by the diagnosis of cancer and chemotherapy, the Psychological domain was also affected, although to a lesser extent, in the quality of life of these women. The occurrence of treatment in their life is experienced in a particular way for each woman. Furthermore, the affected woman's age also influences their adaptation and the biopsychosocial sequelae caused by cancer. Depending on the life cycle of the women, their activities and plans, such as in relation to family and work, are fully affected, especially the femininity and self-esteem in young women. However, anxieties, fears, worries and apprehension are feelings that accompany all of these clients, from diagnosis until the end of cancer treatment. This highlights the need for psychological 
support offered by the whole multidisciplinary team and for therapeutics with psychologists, in addition to support from the family and partner, which has an important role in the adaptation of these patients(10-11,13).

Although studies show that gynecological cancer and antineoplastic chemotherapy may obstruct personal relationships, given the greater reliance on others to perform various tasks and/or the possible changes in physical appearance or body self-image, the Social domain was the least compromised in this study ${ }^{(9-10)}$, followed by the Psychological domain. In a similar study, with ostomy patients suffering from colorectal cancer, it was also found that the most compromised domain was the Physical, and the Social the least compromised(14). It was observed that even with the changes imposed by the disease and treatment, these women are satisfied with their personal relationships, their sexual activities and, especially, with the support they receive from relatives and friends, thus contributing significantly to coping well with this process.

Regarding the general quality of life, it was found that the score obtained in this study, in addition to corresponding to a good quality of life was also superior to those obtained in other studies(13-15).

In relation to the influence of the domains on the general quality of life, it was found that the Psychological domain had the highest correlation, followed by the Physical domain, in this population. The Environment and Social domains were those with lower correlations, although significant. These findings contribute in part to understanding the high values found for the general quality of life in our study group, since the Psychological domain had the second highest score and Environment the lowest.

This study contributes to others related to the evaluation of quality of life of patients with degenerativechronic diseases(16) in general, more specifically in oncology, which have shown to be effective tools for oncology nursing(17), for contributing to the construction of scientific knowledge and the development of skills in the area of oncology.

\section{Conclusions}

Based on data collected and analyzed, it can be said that the perception of quality of life of the women monitored in the development of this study is satisfactory since, due to the recognition of the seriousness of the prognosis, they consider it positive that their physical and psychological capacities, their social relationships and their environment were not affected as they believed they would be, thus enabling the performance of their practical activities in daily life.

This study also concluded that the domains with lower scores should be the subjects of more accurate observation and more efficient and effective intervention in order to provide a better quality of life during chemotherapy.

\section{References}

1. Ministério da Saúde (BR). Instituto Nacional do Câncer. Estimativa 2010: Incidência do câncer no Brasil. Rio de Janeiro (RJ): INCA; 2009.

2. Ministério da Saúde (BR). Instituto Nacional do Câncer. Ações de enfermagem para o controle do câncer: uma proposta de integração ensino-serviço. 2 ed. Rio de Janeiro (RJ): INCA; 2002.

3. Bonassa EMA, Santana TR. Enfermagem em terapêutica oncológica. 3. ed. São Paulo (SP): Atheneu; 2005.

4. Riul da Silva S, Aguillar OM. Assistência de enfermagem em quimioterapia antineoplásica. Rio de Janeiro (RJ): EPUB; 2002.

5. Silva CHD, Derchain SFM. Qualidade de vida de mulheres com câncer ginecológico: uma revisão de literatura. Rev Bras Cancerol. 2006; 52(1):33-47.

6. Fleck MPA, Leal OF, Louzada S, Xavier M, Chachamovich $E$, Vieira $G$, et al. Desenvolvimento da versão em português do instrumento de avaliação de qualidade de vida da OMS (WHOQOL-100). Rev Bras Psiquiatr. 1999; 21(1):19-28.

7. Siqueira KM, Barbosa MA, Boemer MR. O vivenciar a situação de ser com câncer: alguns dês-velamentos. Rev. Latino-Am. Enfermagem. 2007; 15(4):605-11.
8. Ministério da Saúde (BR). Secretaria de Assistência à Saúde. Instituto Nacional do Câncer. Viva Mulher. Programa nacional de controle do câncer do colo do útero e de mama: informações técnico-gerenciais e ações desenvolvidas. Rio de Janeiro (RJ): INCA; 2008

9. Ferreira MLM, Oliveira C. Conhecimento e significado para funcionárias de indústrias têxteis sobre prevenção do câncer do colo-uterino e detecção precoce do câncer da mama. Rev Bras Cancerol. 2006; 52(1):5-15.

10. Sales CACC, Paiva L, Scandiuzzi D, Anjos ACY. Qualidade de vida de mulheres tratadas de câncer de mama: funcionamento social. Rev Bras Cancerol. 2001; 47(3):263-72.

11. Alegrance FC. Qualidade de vida e estratégias de enfrentamento de mulheres com e sem linfedema após câncer de mama.[dissertação]. São Bernardo do Campo (SP): Faculdade de Psicologia e Fonoaudiologia/Universidade Metodista de São Paulo; 2007.

12. Carter BJ. Women's experience of Iymphedema. Oncol Nurs Forum. 1997; 24:876-82. 
13. Rabin EG. Avaliação da qualidade de vida das mulheres com câncer de mama e a percepção de seus parceiros.[dissertação]. Porto Alegre (RS): Faculdade de Ciências Médicas/Universidade Federal do Rio Grande do Sul; 2006.

14. Michelone APC, Santos VLCG. Qualidade de vida de adultos com câncer colorretal com e sem ostomia. Rev. Latino-Am. Enfermagem. 2004 novembro-dezembro; 12(6):875-83.

15. Mansano TC. Qualidade de vida de pacientes com câncer no período de quimioterapia.[Trabalho de Conclusão de Curso]. Campinas (SP): Faculdade de Ciências Médicas (FCM)/ Universidade Estadual de Campinas; 2008.
16. Guimarães FA, Santos MA, Oliveira EA. Qualidade de vida de pacientes com doenças auto-imunes submetidos ao transplante de medula óssea: um estudo longitudinal. Rev. Latino-Am. Enfermagem. 2008 setembro-outubro; 16(5):856-63.

17. Pires AMT, Segreto RA, Segreto HRC. Avaliação das reações agudas da pele e seus fatores de risco em pacientes com câncer de mama submetidas à radioterapia. Rev. Latino-Am. Enfermagem. 2008 setembro-outubro; 16(5):844-9.

Received: Jun. $10^{\text {th }} 2009$

Accepted: Jul. $16^{\text {th }} 2010$ 